\title{
Psychosocial interventions for adults diagnosed with
}

\section{schizophrenia: a theoretical review of studies from 2010-2020}

\author{
Vanshika Beri ${ }^{1 *}$
}

\section{ABSTRACT}

Schizophrenia is one of the psychotic disorders, which includes a significant loss of a touch of reality. It is marked by various positive and negative symptoms. From time to time many researchers came up with different ways to treat this condition. Some of the common interventions are first-generation and second-generation antipsychotic drugs, psychosocial interventions like cognitive behavioral therapies, skills training, psychoeducation, token economy, and so on. However, in the last ten years, many new psychosocial interventions have proven to be successful in treating the condition of schizophrenia. These techniques are not in the mainstream and therefore they are not well known. This review study aimed to highlight some of these techniques so that they could also be used by the clinicians along with the medications. This study is a preliminary step to make these techniques mainstream. Some of these techniques were identified and are explained in this paper.

\section{Keywords: Schizophrenia, Psychosocial Intervention, Review Paper}

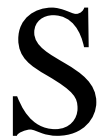
ome people across the world see things, listen to voices that do not exist in reality. They believe in things that do not have any basis in reality. People facing these issues are likely to be diagnosed with psychotic disorders. The main feature of these kinds of disorders is that people lose their touch with reality and they enter into their level of consciousness in which they encounter things that are not real. There are many forms of psychotic disorders, one of the most common forms out of which is schizophrenia. Schizophrenia includes significant disturbance in perception, sense of self, and other cognitive capacities. It includes two broad categories of symptoms positive and negative. Positive symptoms include hallucinations, delusions, formal thought, and speech disruption while negative symptoms include alogia, avolition, apathy, anhedonia, and so on (Butcher, Hooley \& Mineka, 2014).

From time-to-time researchers and clinicians have tried to find out ways through which this condition might be controlled. Many first generations and second-generation antipsychotic drugs were found out that are still used to treat this condition by balancing the neurotransmitters. However, it is observed that the patients can function well if they are also given therapeutic aid besides drugs (Butcher et al., 2014).

\footnotetext{
${ }^{1}$ Amity Institute of Psychology and Allied Sciences, Department of Psychology, India *Responding Author

Received: November 19, 2020; Revision Received: December 23, 2020; Accepted: December 31, 2020

(C) 2020, Beri V.; licensee IJIP. This is an Open Access Research distributed under the terms of the Creative Commons Attribution License (www.creativecommons.org/licenses/by/2.0), which permits unrestricted use, distribution, and reproduction in any Medium, provided the original work is properly cited.
} 
In the Indian context, many people believe that their condition can only be treated by medications and that "just talking" in the therapy will not work. Due to this cultural ideology, people are not aware of different kinds of psychosocial interventions that can also be used besides medications for a speedy recovery and for retaining that recovery.

Some psychosocial interventions are very common and are being used for a very long time. Many authors have covered them and have intensively studied them in the past. Some major social interventions include individual psychoeducational programs to make people with schizophrenia, and their caregivers, aware of what this condition is, what are its causes, and what is the prognosis. This is done in conjunction with other family interventions like providing them with social support. Family intervention includes expressed emotions in which family members get a chance to freely speak about how they feel for the patient and their lives in general. The assumption is that if the family will get a chance of catharsis then that will help them to reduce their anxiety and thereby aggression towards the patient and that might help in recovery (Butcher, et al., 2014; Kearney \& Trull, 2012; Barlow \& Durand, 2012; Sadock, Sadock \& Ruiz, 2007; Adam, Wilson \& Bagnall, 2000). Another intervention is skill training. In this, the person suffering from schizophrenia is taught social skills that are necessary to live among a group of people in a society and life skills that are essential for independent living like earning, carrying out basic household work and so on (Butcher, et al., 2014; Kearney, et al., 2012; Barlow, et al., 2012; Sadock, et al., 2007; Adam, et al., 2000). Besides social, there are some community-based interventions also. These include case management in which a case manager that is appointed for the patient takes care of all the needs of the patient on one to one basis and another technique is assertive community treatment which is cost-effective because through these the patient spends less time in hospital. People who believe in community services are the one who gets the major advantage form this (Butcher, et al., 2014 Adam, et al., 2000)

Many psychological interventions that are used for treating schizophrenia include cognitive behavioral therapy. This technique has proved to be successful in treating the condition. The patients' in this are required to challenge their thought processes and beliefs by providing rational evidence. Gradually, this makes them more aware of their condition and that leads to improvement (Butcher, et al., 2014; Kearney, et al., 2012; Barlow, et al., 2012; Sadock, et al., 2007; Adam, et al., 2000). Another approach is psychoanalysis. However, researchers have noted that the approach is not very successful for most of the patients (Adam et al., 2000). Yet another approach is the token economy in which patients are given tokens in terms of rewards whenever they behave in the ways that are expected from them. This technique has proved to be the only technique that is proved successful in treating negative symptoms (Adam, et al., 2000). Besides these techniques, there are upcoming techniques that are not in the mainstream but are being used for treating the condition, and therefore it is important to put light upon them.

\section{METHODOLOGY}

\section{Purpose}

The study was a review study that was done to trace different kinds of psychosocial interventions that are used to treat this condition around the world. The main aim of the study is to put light on psychosocial interventions that are not in the mainstream. In other words, that are not so commonly used in some parts of the world. 


\section{Procedure}

For the study, past pieces of literature were traced with the help of various search engines like google scholar, PubMed, ResearchGate, and so on. Studies that met the inclusion criteria (in table 1) were used for the study. The screening procedure is given in figure 1.

\section{Table 1 Inclusion and Exclusion Criteria}

\begin{tabular}{llll}
\hline \multicolumn{2}{l}{ Inclusion Criteria } & Exclusion Criteria \\
\hline 1 & $\begin{array}{l}\text { Studies that are done between 2010-2020 } \\
2\end{array}$ & $\begin{array}{l}\text { Studies that are done on schizophrenia only } \\
2\end{array}$ & $\begin{array}{l}\text { Studies that are done before 2010 } \\
\text { Studies that are done on other } \\
\text { psychotic disorders like } \\
\text { schizoaffective and so on. } \\
\text { Studies that are done on 18- years } \\
\text { old and below age groups }\end{array}$ \\
4 & $\begin{array}{l}\text { Studies that are done on an adult population } \\
\text { Both primary and secondary kinds of } \\
\text { research }\end{array}$ & 4 & $\begin{array}{l}\text { Studies that focused on } \\
\text { pharmacological methods } \\
\text { Both qualitative and quantitative research }\end{array}$ \\
6 & 5 & $\begin{array}{l}\text { Studies that focused on } \\
\text { community-based interventions } \\
\text { interventions }\end{array}$ & \\
\hline
\end{tabular}

\section{Figure 1 Screening Procedure}

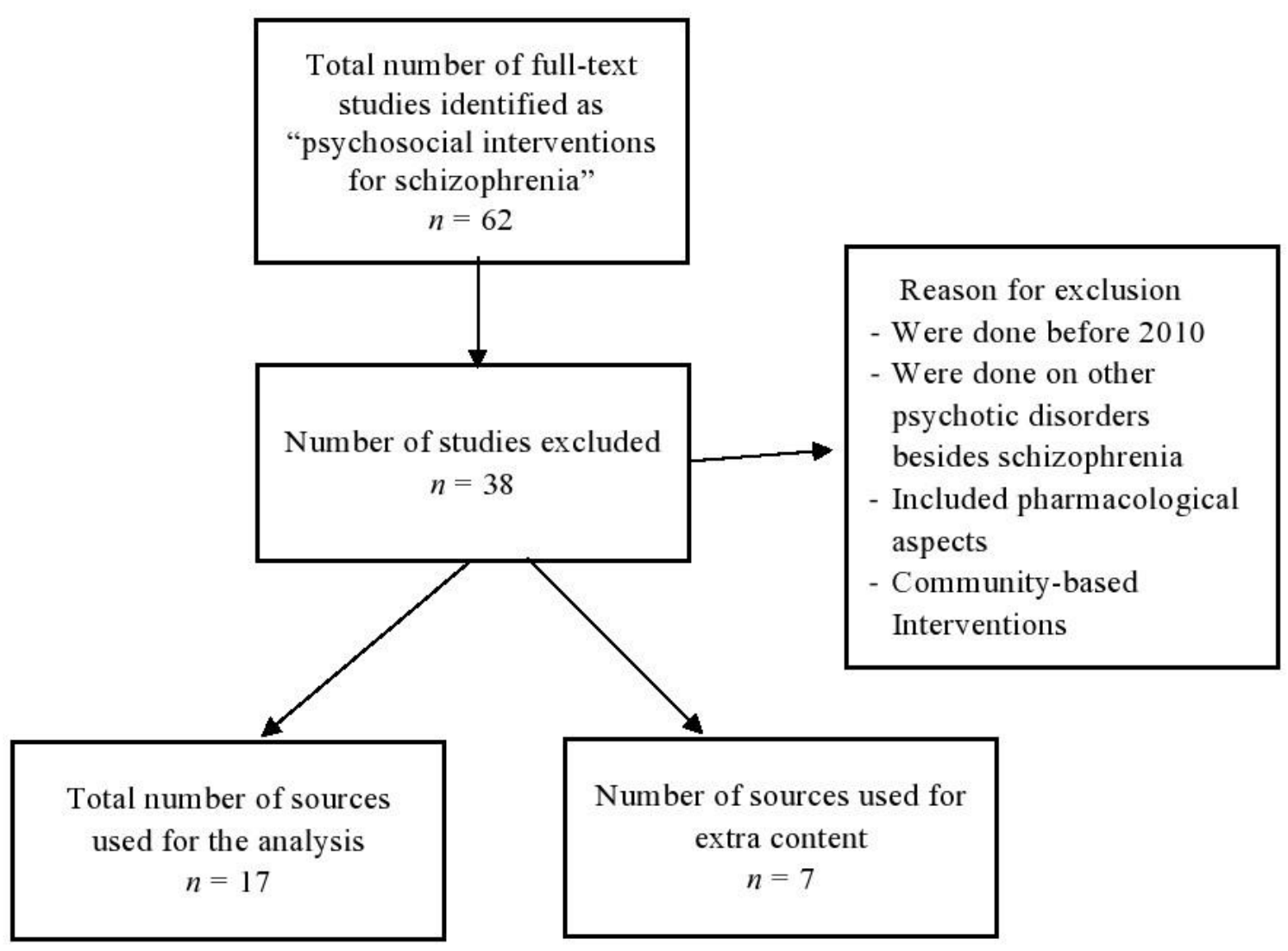




\section{RESULTS}

Besides the commonly used techniques, the modern techniques that are upcoming for treating schizophrenia that were identified in the literature are mentioned in table 2.

\section{Table 2 Upcoming Psychosocial Interventions}

\begin{tabular}{lll}
\hline Intervention & Author, year & Key findings \\
\hline $\begin{array}{l}\text { Smart-Phone } \\
\text { apps and }\end{array}$ & Camacho et al. & Found mobile apps to be useful for monitoring and \\
(2019) & providing appropriate intervention.
\end{tabular}

Web-Based

providing appropriate intervention.

Interventions

Arnold et al.

(2020)
Found web-based intervention as advantageous as it is a systematic approach and the emails acted as a successful reminder. However, some challenges also came into the picture like connectivity issues, lack of time, resources, and space.

\begin{tabular}{ll}
\hline Yoga and & Budak and Yilmaz \\
Meditation & (2019) \\
& Sistig et al (2015)
\end{tabular}

Sistig et al (2015)

Found yoga to be useful for improving clinical insight and adherence to treatment.

Yoga provided a deep sense of relaxation, increased confidence, decreased anxiety, provided energy, increased level of concentration, and increased the level of motivation to engage with life.

Vancampfort et al Concluded that yoga can be used as an additional (2012) treatment for treating schizophrenia.

Govindaraj et al. Developed a validated module (by ten experts) that (2016) will contribute to the improvement of positive, negative, and cognitive symptoms along with the side effects of medical treatment.

\section{Exercise}

Firth et al. (2015)

Firth et al. (2016)

Both positive and negative symptoms can be reduced with the help of a 90-minutes of moderateto-vigorous exercise and can help in reducing neurological impairment.

Supported the earlier findings and further added that the release of endorphins will lead to a reduction in depression caused due to schizophrenia.

Sabe et al. (2020) Exercise helps in reducing negative symptoms.

Vogel et al. (2019) Reduction in negative symptoms could be observed.

\section{Religion and} Spirituality

Gearing et al. (2011)

Smolak et al. (2013)

Mohr et al. (2011)

Grover et al. (2014)

Acceptance Yildiz (2020)

People have delusions and hallucinations which have religious content.

Evaluated various religious coping strategies.

Found reducing negative symptoms and improved social functioning and quality of life among people with schizophrenia.

Incorporation of religious means is important in the biopsychosocial model for treating schizophrenia. 


\begin{tabular}{lll}
\hline Intervention & Author, year & Key findings \\
\hline $\begin{array}{l}\text { and } \\
\text { Commitment } \\
\text { Therapy } \\
\text { (ACT) and } \\
\begin{array}{l}\text { Motivational } \\
\text { Interviewing } \\
\text { (MI) }\end{array}\end{array}$ & $\begin{array}{l}\text { psychological flexibility along with control of } \\
\text { symptoms. }\end{array}$ \\
& $\begin{array}{l}\text { Fiszdon et al } \\
\text { (2016) }\end{array}$ & $\begin{array}{l}\text { MI is effective in improving commitment towards } \\
\text { cognitive training. } \\
\text { Counseling based ACT with MI increases the level } \\
\text { of treatment motivation in individuals with } \\
\text { schizophrenia. }\end{array}$ \\
\hline
\end{tabular}

\section{Smart-Phone Apps and Web-Based Interventions}

In today's time where technology is growing at an immense rate, many researchers and clinicians have started using web-based smart applications. These applications can be utilized by the patients as per their convenience. Some of these applications that are utilized for the treatment of psychosis were identified in a systematic review done by Camacho et al. (2019). These apps are performed for a variety of functions like offering support by the therapist through mobile apps and tries to improve the daily functioning of the client. The apps also assign various assessments for the clients and are also utilized for getting feedbacks. Some apps are also used for increasing the motivation level in clients and increase interaction between the therapists and their peers. The apps are also beneficial for dealing with clients who live in remote areas and find difficulty in meeting with the therapist from time to time (Camacho et al., 2019).

A study by Arnold et al. (2020) reported some pros and cons of using web-based apps. Firstly, they reported that the apps allowed clients and therapists to follow a systematic approach in which every aspect of the treatment was being tracked. Secondly, the emails and the notifications that the clients received acted as a motivator for them to open the app. Thirdly, many people felt that they got the support of peers through the app and lastly many clients felt that they were gaining control over themselves (Arnold et al., 2020). However, many challenges were felt while using the app. Clients reported that after feeling a little better, their main priority was to look after their household chores and other things. Clients were facing the problem of a lack of resources to use the apps. While some patients had paranoia, they felt that they are being tracked all the time and that resulted in a sense of discomfort and thereby caused fluctuations in their well-being. They were also overwhelmed by the strict navigation of them by the apps (Arnold et al., 2020). The applications can prove to be useful in this time of pandemic where everyone is finding it difficult to visit a therapist. There is a need to highlight this area of study so that more people can become aware of these kinds of provisions.

\section{Yoga and Meditation}

Yoga and meditation are traditional techniques that are used in addition to medications to treat many diseases, both physical and psychological. Many researchers have designed interventions based on various techniques of yoga. For instance, Budak and Yilmaz (2019) formulated a program in which they introduced physical relaxation, Surya namaskar, various asanas, pranayama, and meditation. A similar program was formulated which was based on 
hatha yoga, modern yoga (based on the principles of Patanjali), breathing techniques, and meditation (Sistig et al. 2015).

Similar modules were also formulated in the Indian context. A yoga module formulated by Govindaraj et al (2016) included Surya Namaskar, asanas, pranayama, meditation/ relaxation, and yogic counseling. The findings revealed that asanas like vakrasana, ustrasana, bhujangasana, salabhasana dhanurasana, matasyasana were useful for improving the condition of schizophrenia whereas, pascimottanasana and kapalbhati were not that useful (Govindaraj et al 2016).

The findings of many studies revealed yoga to be useful for improving clinical insight and adherence to treatment (Budak \& Yilmaz, 2019). Further, it provided a deep sense of relaxation, increased confidence, decreased anxiety, provided energy, increased level of concentration, and increased the level of motivation to engage with life (Sistig et al. 2015). Overall, besides medications, yoga can be used as an additional treatment for treating schizophrenia (Vancampfort et al, 2012).

\section{Exercise}

An exercise is a form of physical activity that helps people to maintain their physical and mental health. Studies have found out that both positive and negative symptoms can be reduced with the help of a 90-minutes of moderate-to-vigorous exercise (Firth et al., 2015). One of the qualitative studies also reported similar findings. Firth et al., (2016) reported that if patients overcome the barriers of anxiety and if a trained supervisor helps them with the exercise, then that will help in reducing the positive symptoms and negative symptoms. A meta-analysis on physical exercise and schizophrenia exclusively reported that it is useful for overcoming the negative symptoms (Sabe, et al., 2020; Vogel et al., 2019). It has also been found out that there are some aspects of schizophrenia that are resistant to conventional treatment, those symptoms can be reduced with the help of exercise (Firth et al., 2015). Importantly if exercise is implemented at the correct time then that will reduce the neurological impairments or will prevent the impairment to occur (Firth et al., 2015). Exercise also helps in the secretion of endorphins which eventually will lead to a reduction in depressive symptoms caused due to psychotic conditions (Firth, et al., 2016).

\section{Religion and Spirituality}

Religion is very strongly associated with schizophrenia. Most people have delusions and hallucinations that have religious themes (Gearing et al., 2011), and that people who are high on religiosity are more likely to have them (Huang, et al 2011). Since religion is associated with schizophrenia, it can be said that people who are high on religiosity use religious strategies to overcome their problems. One of the methods is religious coping in which patients use their religious beliefs to overcome their negative thoughts and to increase their willpower. Many studies have evaluated different kinds of coping strategies (Smolak et al., 2013). Religious practices help in reducing negative symptoms and improve social functioning and quality of life among people with schizophrenia (Mohr et al., 2011). Grover et al. (2014) in their review study explained that the biopsychosocial model should be followed while treating schizophrenia, in which religious practices should be integrated. This area has not been explored much by the researchers, a reason why most clinicians are not aware of it and do not include it in their treatment (Grover et al., 2014). There is a need to conduct more researches on religiosity as an add-on method of treatment for schizophrenia. 


\section{Acceptance and Commitment Therapy and Motivational Interviewing}

Individuals with schizophrenia display a lack of motivation for going to psychosocial rehabilitation which might lead to a reduction in the effectiveness of the treatment (Fiszdon et al., 2016). Therefore, besides medication, now the technique of Acceptance and Commitment Therapy (ACT) and Motivational Interviewing (MI) is being used, so that the level of treatment motivation could be increased. The basic idea of ACT is that the betterment in the condition will come only if the patients become aware of the symptoms and then accept them and differentiate them from oneself, only then the commitment to improve the symptoms will come (Harris, 2019). Yildiz and Aylaz (2020) explained the two major objectives of ACT, first effectively dealing with negative and painful thoughts, and second, to lead a meaningful life. ACT has proved to be effective in increasing motivation and psychological flexibility along with control of symptoms in the patients (Yildiz, 2020). The same is the case with MI, which also has proved to be effective for patients with schizophrenia. It has been found that it can be effective in improving commitment towards cognitive training (Fiszdon et al., 2016).

Yildiz and Aylaz (2020) identified that there are some components of ACT and MI that are overlapping. Therefore, they assessed what impact will this treatment combination has on patients. Specifically, the impact on treatment motivation was assessed because so many patients are not motivated enough to take medications due to side effects. This kind of study has been done for the first time where both these techniques are used together as a combination (Yildiz and Aylaz, 2020). They found that when this combination is implemented, patients reported an increase in the level of efforts to control their illness and an increase in the ability to participate in daily life activities and social relations, leading to a value-oriented life. Overall, they concluded that ACT along with MI improves the treatment motivation in people with schizophrenia.

\section{DISCUSSION}

Schizophrenia is one of the psychotic disorders in which the patient loses touch with reality. This disorder is marked with positive symptoms like hallucinations, delusions, and negative symptoms like alogia, avolition, asociality, and so on. The disorder is so complex that a single medication is not enough for its treatment. Along with many first-generation and second-generation antipsychotics, many psychosocial interventions are also done on the patients for a speedy recovery and to prevent relapse (Butcher et al., 2014).

Many traditional psychosocial interventions are given to patients. These majorly include individualized psychoeducational program, family interventions like expressive emotions, skill training (life skills and social skills), case management, assertive community treatment, cognitive behavioral therapy, psychoanalysis, token economy, and so on (Butcher, et al., 2014; Kearney, et al., 2012; Barlow, et al., 2012; Sadock, et al., 2007; Adam, et al., 2000). These techniques are mentioned almost everywhere and are widely used along with medications to treat the condition of schizophrenia.

However, some new upcoming techniques are now being used but are not mentioned in the famous books because they are still not there in the mainstream. This paper aimed to highlight some of these techniques. Some techniques that are widely used for other psychological and physical conditions, which have now proved to be successful for neurodevelopmental conditions like schizophrenia are yoga, meditation, and exercise. 
Yoga helps in improving clinical insight and adherence to treatment (Budak \& Yilmaz, 2019). It provides a deep sense of relaxation, increase the level of confidence, reduces anxiety, provides energy, increase the level of concentration, and increase the level of motivation to engage with life (Sistig et al. 2015). While physical exercise is useful for overcoming the negative symptoms (Sabe, et al., 2020; Vogel et al., 2019). Further, if exercise is implemented at the correct time then that will reduce the neurological impairments or will prevent the impairment to occur (Firth et al., 2015). Exercise also helps in the secretion of endorphins which also provide happiness and calmness to the patient (Firth, et al., 2016).

Another technique is Acceptance and Commitment Therapy (ACT) and Motivational Interviewing (MI). The basic idea of ACT is that the person becomes aware of the symptoms and then accepts them by differentiating them from oneself. One has to face the negative thoughts and the pain and then only commitment to recovery will come. Further, MI along with ACT will motivate the patient to accept the treatment and medications, because people usually skip them due to side effects (Yildiz, 2020; Yildiz and Aylaz, 2020; Fiszdon et al., 2016). ACT along with MI will increase their level of effort to control their illness and increase their ability to participate in daily life activities and social relations, leading to a value-oriented life (Yildiz and Aylaz, 2020).

Besides, there are techniques like religion and spirituality, which have a strong association with schizophrenia, as people usually have delusions and hallucinations which have religious content (Gearing et al., 2011). Religious practices help in reducing negative symptoms and improve social functioning and quality of life in schizophrenics (Mohr et al., 2011). People who associate themselves with some religion and believe in it can feel better if their treatment is also associated with their beliefs and therefore therapists should include religion in the biopsychosocial approach to treat schizophrenia (Grover et al., 2014).

Finally, a technique, about which most of the therapists are unaware is the use of smartphone apps and web-based techniques that are exclusively designed for treating schizophrenia. A list of such apps was identified in an extensive review paper by Camacho et al. (2019). These apps offer support to therapists through mobile phones and try to improve the daily functioning of the client by keeping track of their activities. The apps also assign various tasks and assessments to the clients and are also used for feedbacks. Some apps are also used for increasing the motivation level in clients and increase interaction between therapists and peers (Camacho et al., 2019). While Arnold et al (2020) reported other advantages like keeping a record of treatment, emails act as reminders and motivators and clients started feeling a sense of control over themselves. However, the study also reported some disadvantages like issues of time, resources, and connectivity. While some patients have an issue of paranoia, they felt that they are being tracked all the time which gives them a sense of discomfort and thereby causing fluctuations in their well-being (Arnold et al., 2020).

These are some of the techniques that are now being used for the treatment of schizophrenia. However, they are not so popular because they are still not there in the mainstream.

\section{Implications, Limitations, and Future Suggestions}

The main objective of this paper was to highlight some of the techniques that are being used for the treatment of schizophrenia, however, they are not in the mainstream. Techniques like 


\section{Psychosocial interventions for adults diagnosed with schizophrenia: a theoretical review of studies}

from 2010-2020

yoga, exercise, and meditation are used widely for other disorders but now the studies have shown that these can also be used in the case of a neurodevelopmental condition like schizophrenia and therefore it is important to make clinicians and therapists aware of it. Further, a technique like acceptance and commitment therapy can be integrated with similar techniques like motivational interviewing to treat the condition.

New techniques like smartphone apps and web-based techniques are also used nowadays. Especially in today's time where the world is fighting a pandemic, people are not able to take care of their mental health because they cannot visit their therapists. In this case, these apps can be very useful. Finally, the technique of religion and spirituality is not given much importance. It is important to highlight all these techniques and bring them to the mainstream.

One of the limitations of this paper is that it did not take any one intervention and studied it in detail but took papers on different topics of interventions. Future authors can study any one intervention in detail. Another limitation is that this paper is not context-specific. Paper from around the world was taken into consideration. Future studies can be done in a specific region of the world.

\section{CONCLUSION}

The paper highlighted some of the psychosocial interventions that have been studied in the last ten years to treat schizophrenia. Some of these interventions are smartphone apps, webbased applications, religion, spirituality, acceptance and commitment therapy, and motivational interviewing, yoga, meditation, and exercise. These techniques are widely used for other disorders but not many clinicians are aware that they can also be used for treating a neurodevelopmental condition like schizophrenia. It is important to highlight the fact that all these techniques have proved to be successful in treating some or other aspects of schizophrenia.

\section{REFERENCES}

Adams, C., Wilson, P. \& Bagnall, A-M. (2000). Psychosocial interventions for schizophrenia. Quality in Health Care, 9, 251-256. http://dx.doi.org/10.1136/qhc.9.4.251

Arnold, C., Williams, A. \& Thomas, N. (2020). Engaging with a web-based psychosocial intervention for psychosis: qualitative study of user experiences. JMIR Mental Health, 7(6), e16730. 10.2196/16730.

Barlow, D. H. \& Durand, V. M. (2012). Abnormal Psychology: An Integrative Approach. Sixth Edition. Wadsworth Cengage Learning.

Budak, F.K. \& Yilmaz, E. (2019). The effect of yoga on clinical insight and medication adherence in patients with schizophrenia - A randomized controlled trial. European Journal of Integrative Medicine, 30(September) 100949. https://doi.org/10.1016/j.eujim.2019.100949

Butcher, J. N., Hooley, J. M. \& Mineka, S. (2014). Abnormal psychology. Sixteenth edition. Pearson.

Camacho, E., Levin, L. \& Torous, J. (2019). Smartphone apps to support coordinated specialty care for prodromal and early course schizophrenia disorders: systematic review. J Med Internet Res, 21(11), e16393. 10.2196/16393 
Firth, J., Carney, R., Jerome, L., Elliott, R., French, P. \& Yung, A.R. (2016). The effects and determinants of exercise participation in first-episode psychosis: a qualitative study. BMC Psychiatry, 16, 36. https://doi.org/10.1186/s12888-016-0751-7

Firth, J., Cotter, J., Elliott, R., French, P. \& Yung A. R. (2015). A systematic review and meta-analysis of exercise interventions in schizophrenia patients. Psychological Medicine, 45, 1343-1361. 10.1017/S0033291714003110

Fiszdon, J. M., Kurtz, M. M., Choi, J., Bell, M. D., \& Martino, S. (2016). Motivational interviewing to increase cognitive rehabilitation adherence in schizophrenia. Schizophrenia Bulletin, 42(2), 327-334. https://doi.org/10.1093/schbul/sbv143

Gearing RE, Alonzo D, Smolak A, McHugh K, Harmon S, Baldwin S. (2011). Association of religion with delusions and hallucinations in the context of schizophrenia: Implications for engagement and adherence. Schizophrenia Research, 126(1-3),150163. https://doi.org/10.1016/j.schres.2010.11.005

Govindaraj, R., Varambally, S., Sharma, M. \& Gangadhar, N. (2016). Designing and validation of a yoga-based intervention for schizophrenia. International Review of Psychiatry, 28(3), 323-326. http://dx.doi.org/10.3109/09540261.2016.1151404

Grover, S., Davuluri, T. \& Chakrabarti, S. (2014). Religion, spirituality, and schizophrenia: A review. Indian Journal of Psychological Medicine, 36(2), 119-124. 10.4103/02537176.130962

Harris, R. (2019). ACT made simple: An easy-to-read primer on acceptance and commitment therapy. New Harbinger Publication, Inc.

Huang, C.L., Shang, C.Y., Shieh, M.S., Lin H.N. \& Su, J.C. (2011). The interactions between religion, religiosity, religious delusion/hallucination, and treatment-seeking behavior among schizophrenic patients in Taiwan. Psychiatry Research, 187(3), 34753. https://doi.org/10.1016/j.psychres.2010.07.014

Kearney, C. A. \& Trull, T. J. (2012). Abnormal Psychology and Life: A Dimensional Approach. Wadsworth Cengage Learning.

Mohr, S., Perroud, N., Gillieron, C., Brandt, P-Y., Rieben, I., Borras, L. \& Huguelet, P. (2011). Spirituality and religiousness as predictive factors of outcome in schizophrenia and schizo-affective disorders. Psychiatry Research, 186(2-3), 177182. https://doi.org/10.1016/j.psychres.2010.08.012

Sabe, M., Kaiser, S. \& Sentissi, O. (2020). Physical exercise for negative symptoms of schizophrenia: Systematic review of randomized controlled trials and meta-analysis. General Hospital Psychiatry, 62(January-February), 13-20. https://doi.org/10.1016/j.genhosppsych.2019.11.002

Sadock, B.J., Sadock, V.A. \& Ruiz, P. (2015). Synopsis of Psychiatry Behavioral Sciences/Clinical Psychiatry. Eleventh Edition. Wolters Kluwer.

Sistig, B., Lambrecht, I. \& Friedman, S. H. (2015). Journey back into body and soul - An exploration of mindful yoga with psychosis. Psychosis, 7(1), 25-36, http://dx.doi.org/10.1080/17522439.2014.885556

Smolak, A., Gearing, R.E., Alonzo, D., Baldwin, S., Harmon, S. \& McHugh, K. (2013). Social support and religion: mental health service use and treatment of schizophrenia. Community Mental Health Journal, 49, 444-450. https://doi.org/10.1007/s10597-012-9536-8

Vancampfort, D., Vansteelandt, K., Scheewe, T., Probst, M. Knapen, J., De Herdt, A. \& De Hert, M. (2012). Yoga in schizophrenia: a systematic review of randomised controlled trials. Acta Psychiatrica Scandinavica, 126, 12-20. 10.1111/j.16000447.2012. 01865.x 
Vogel, J. S., Gaag, M. V., Slofstra, C., Knegtering, H., Bruins, J., \& Castelein, S. (2019). The effect of mind-body and aerobic exercise on negative symptoms in schizophrenia: A meta-analysis. Psychiatry Research, 279(September), 295-305. 10.1016/j.psychres.2019.03.012

Yildiz, E. \& Aylaz, R. (2020). How counseling based on acceptance and commitment therapy and supported with motivational interviewing affects the perceptions of treatment motivation in patients diagnosed with schizophrenia: a qualitative study. Journal of the American Psychiatric Nurses Association. 00(0), 1-15. $10.1177 / 1078390320945380$

Y1ldiz, E. (2020). The effects of acceptance and commitment therapy in psychosis treatment: A systematic review of randomized controlled trials. Perspectives in Psychiatric Care, 56(1), 149-167. https://doi.org/10.1111/ppc.12396

\section{Acknowledgement}

I would like to thank Mr. Sundeep Katevarapu for his constant support and Guidance.

\section{Conflict of Interest}

The author declared no conflict of interest.

How to cite this article: Beri V. (2020). Psychosocial interventions for adults diagnosed with schizophrenia: a theoretical review of studies from 2010-2020. International Journal of Indian Psychology, 8(4), 1462-1472. DIP:18.01.158/20200804, DOI:10.25215/0804.158 